\title{
BMJ Open Mental health condition of college students compared to non-students during COVID-19 lockdown: the CONFINS study
}

\author{
Julie Arsandaux (D) , ${ }^{1}$ Ilaria Montagni (D) , ${ }^{1}$ Mélissa Macalli, ${ }^{1}$ Nathalie Texier, ${ }^{2}$ \\ Mathilde Pouriel, ${ }^{2}$ Raphaël Germain, ${ }^{2}$ Adel Mebarki, ${ }^{2}$ Shérazade Kinouani (D) , \\ Marie Tournier, ${ }^{1,3}$ Stéphane Schuck, ${ }^{2}$ Christophe Tzourio (i) ${ }^{1}$
}

To cite: Arsandaux J, Montagni I, Macalli M, et al. Mental health condition of college students compared to non-students during COVID-19 lockdown: the CONFINS study. BMJ Open 2021;11:e053231. doi:10.1136/ bmjopen-2021-053231

- Prepublication history and additional supplemental material for this paper are available online. To view these files, please visit the journal online. (http://dx.doi.org/10.1136/ bmjopen-2021-053231).

Received 10 May 2021 Accepted 09 July 2021

Check for updates

(C) Author(s) (or their employer(s)) 2021. Re-use permitted under CC BY-NC. No commercial re-use. See rights and permissions. Published by BMJ.

${ }^{1}$ Bordeaux Population Health, Université de Bordeaux, Talence, France

${ }^{2}$ Kappa Santé, Paris, France

${ }^{3}$ Charles Perrens Hospital,

Bordeaux, France

Correspondence to

Pr Christophe Tzourio;

christophe.tzourio@u-bordeaux. $\mathrm{fr}$

\section{ABSTRACT}

Objectives To estimate the effect of student status on mental health condition during COVID-19 general lockdown in France.

Design Cross-sectional analysis comparing students and non-students recruited in the same study.

Setting Participants of the web-based CONFINS study implemented during the general lockdown in France in spring 2020.

Participants 2260 participants (78\% women) including 1335 students $(59 \%)$.

Primary and secondary outcome measures Through an online questionnaire, participants declared if they have experienced suicidal thoughts, coded their perceived stress on a 10-points scale and completed validated mental health scales (Patient Health Questionnaire-9 for depressive symptoms, Generalised Anxiety Disorder-7 for anxiety symptoms) during the last 7 days. The effect of college student status on each mental health condition was estimated using multivariate logistic regression analyses. Stratified models for students and non-students were performed to identify population-specific factors. Results Student status was associated with a higher frequency of depressive symptoms (adjusted OR $(\mathrm{aOR})=1.58 ; 95 \% \mathrm{Cl} 1.17$ to 2.14 ), anxiety symptoms (aOR=1.51; $95 \% \mathrm{Cl} 1.10$ to 2.07), perceived stress $(n=1919, a 0 R=1.70,95 \% \mathrm{Cl} 1.26$ to 2.29$)$ and suicidal thoughts ( $n=1919$, a0R=1.57, 95\% $\mathrm{Cl} 0.97$ to 2.53 ). Lockdown conditions that could be potentially aggravating on mental health like isolation had a higher impact on students than on non-students.

Conclusions College students were at higher risk of mental health disturbances during lockdown than nonstudents, even after taking into account several potential confounding factors. A close follow-up and monitoring of students' mental health status is warranted during lockdown periods in this vulnerable population.

\section{INTRODUCTION}

Young adults are particularly exposed to psychiatric disorders which often start in young adulthood. College students have been identified as a vulnerable population and have higher prevalence of psychiatric

\section{Strengths and limitations of this study}

- Direct comparison between a large sample of students and non-students recruited during the same period in a unique study.

- Large collection of variables, including lockdown conditions, allowing to investigate factors potentially associated to mental conditions for both students and non-students.

- Since students and non-students were volunteers, generalisation of the results could be limited.

- The cross-sectional design did not allow studying the temporal relationship between lockdown and mental health condition.

symptoms (eg, depressive symptoms, anxiety symptoms and suicidal risk) than other adults. ${ }^{1-4}$ In this population, and particularly in the first years at university, a high level of stress-related to academic achievement, a low self-esteem and depressive symptoms are frequently reported. ${ }^{5-7}$

The unprecedented context of 2020 with the SARS-CoV-2 pandemic and its consequences have raised fears of its psychological impact in the population and more particularly in the fragile population of college students. ${ }^{8}$ In February 2020, the SARS-CoV-2 epidemic, causing the COVID-19 disease, hit France which is one of the most affected countries in the world in number of cases and deaths. ${ }^{9}$ To contain the spread of the epidemic, France established a general lockdown from 17 March to 11 May 2020. During previous lockdowns (eg, SARS epidemic in 2013), it has been shown that quarantine had by itself an impact on mental health (depression, post-traumatic stress symptoms, confusion, anger, suicide). ${ }^{10}{ }^{11}$ These findings have also been found in the general population during the first COVID-19 lockdown period 
at the beginning of $2020 .{ }^{12-16}$ Regarding the specific population of college students, there is a growing literature concerning the psychological impact of lockdown on this already vulnerable population. ${ }^{17-27}$ However, no direct comparison of this impact between students and non-students has been published and it remains uncertain whether students are indeed at higher risk of mental health disturbances during lockdown.

The objectives of this study were to estimate the effect of lockdown on mental health conditions (depressive symptoms, anxiety symptoms, suicidal thoughts and perceived stress) in college students and to compare directly their frequency and associated factors to a sample of nonstudents recruited in the same study.

\section{MATERIAL AND METHODS}

Data source, study design and study population

This study is based on the CONFINS study (www.confins. org), a prospective online population-based cohort study of adult volunteers in France which was set up in April 2020 during the first COVID-19 national lockdown, established between March and May 2020. The main objective of the CONFINS study was to investigate the impact of the COVID-19 pandemic and the general lockdown on the well-being and mental health of the population. A large communication campaign was deployed in France on social media and press. Several professional (health workers) and university networks relayed recruitment information. The eligibility criteria were to be more than 18 years old and locked down in the French territory until the end of the general lockdown in France (11 May 2020). Enrolled participants signed in a secured website and completed questionnaires online. The baseline questionnaire collected sociodemographic information, medical history, lockdown conditions, mental health parameters, as well as opinions and beliefs. The current study is based on data collected during the first general lockdown in France (until 11 May 2020).

\section{Patient and public involvement}

No participants were involved in setting the research questions or measurements or in developing plans for the design of the study. No participants were asked to advise on the interpretation or writing up of results. However, the results of the research are disseminated to study participants via the CONFINS cohort website and social media and by means of a quarterly newsletter sent to all participants.

\section{Measures}

Outcome: mental health conditions

\section{Depressive symptoms}

Depressive symptoms were measured using the Patient Health Questionnaire-9 (PHQ-9) ${ }^{28}{ }^{29}$ modified to assess symptoms within the last 7 days (instead of the last 14 days) for close monitoring purpose. Items are rated from 0 to 3 according to the increased frequency of experiencing difficulties in each area covered. Scores are summed and can range from 0 to 27. Higher scores represent higher depressive symptoms. We used the validated French version of the PHQ-9. ${ }^{30}$ Since the distribution of the score was not normal, we used a validated cut-off of 10 to define the presence of depressive symptoms. ${ }^{2831}$

\section{Anxiety symptoms}

Anxiety symptoms were measured using the Generalised Anxiety Disorder-7 (GAD-7) ${ }^{32}$ modified to assessed symptoms within the last 7 days (instead of the last 14 days). Items are rated from 0 to 3 according to the increased frequency of experiencing difficulties in each area covered. Scores are summed and can range from 0 to 21. Higher scores represent higher anxiety symptoms. We used the validated French version of the GAD-7. ${ }^{33}$ Since the distribution of the score was not normal, we used a validated cut-off of 10 to define the presence of anxiety symptoms. $^{32}$

\section{Suicidal thoughts}

Participants reported if they experienced suicidal thoughts during the last 7 days ('During the past 7 days, have you ever thought about killing yourself (suicidal ideas)': with the responses 'no, never' and 'yes, sometimes' or 'yes, on multiple occasions' considering together for analysis purpose).

\section{Perceived stress}

Participants rated their current stress on a 10 points-scale ('How worried or stressed are you right now on a scale of $0-10$ '), with 0 representing the lowest level of stress and 10 the highest. Since the distribution of the score was not normal, we used a cut-off of 7 to defined high perceived stress (corresponding approximately to the third quartile of the distribution).

\section{Student status}

Participants declared if they were current college students or not and were asked about specific information according to their academic situation (eg, study field, university year) if they were students and their professional situation otherwise.

\section{Covariates/other exposures}

Sociodemographic information included sex and age (in years), marital situation (in a relationship or not) and education level. The level of education was coded differently for students and non-students: less than a secondyear university level or currently in their first or second year for students; holding a second-year university level or currently in their third year for students; holding more than a second-year university level or currently in their fourth or more year for students. Other variables possibly influencing mental health were recorded like working or studying in the medical field, having a history of psychiatric disorder (depression, bipolar disorders, generalised anxiety), history of another disease exposing to severe forms of COVID-19 (cardiovascular, respiratory, chronic 
digestive disease, cancer, diabetes). Other covariates/ exposures were collected for students: having a paid activity (student job) and self-rated financial situation during childhood (correct, difficult or very difficult vs comfortable or very comfortable), as well as for nonstudents: having a high professional position and having a stable professional situation (open-ended work contract).

Information related to the COVID-19 pandemic or lockdown was also recorded: week of inclusion (W14-15 corresponding to 30 March to 12 April, W16-17 corresponding to 13 April to 26 April and W18-19 corresponding to 27 April to 11 May); being in a high-risk region (defined by region that registered more than 10 deaths during the week 14); having friends or relatives with COVID-19 or COVID-19 suspicion; being alone in lockdown accommodation; being in lockdown at home (in the same place than before lockdown); lockdown accommodation with an outdoor space (like a balcony or a garden) or not and surface (in $\mathrm{m}^{2}$ ); having a pet; doing physical exercise during lockdown. Non-students were asked whether they were working remotely during lockdown or not.

\section{Statistical analysis}

First, we described the study sample overall and in both student and non-student categories. Second, we estimated the effect of student status on each mental condition (ie, depressive symptoms, anxiety symptoms, suicidal thoughts and perceived stress) using separated logistic regression models. Three multivariate models were built using a different adjustment: model 1 adjusted for age and sex, model 2 adjusted for age, sex and variables not related to the COVID-19 pandemic or lockdown (ie, being in a relationship, education level, working or studying for the medical sector, history of psychiatric disease, history of other disease at risk for COVID-19) and model 3 adjusted for age, sex, precited variables not related to the COVID-19 pandemic or lockdown and variables related to the COVID-19 pandemic or lockdown (ie, week of inclusion in the cohort, being in lockdown in a high-risk region, acquaintance or family with COVID-19 or COVID-19 suspicion, being in lockdown alone, lockdown accommodation with an outdoor space, having a pet, lockdown accommodation surface, physical activity during lockdown). We estimated OR, their 95\% CI and the $p$ value of the Wald test (and $p$ value of the type 3 test for categorical variables) related to the effect of student status. We performed secondary analysis restricting the sample to young adults ( $\leq 30$ years old) to better take into account potential confusion by age.

Third, we computed a general model for each mental health condition among students and non-students separately to investigate the associated factors of these two populations. We performed the same model than primary analysis extending the list of exposure with all factors (model 3) and entering specific variables for students (ie, paid activity and financial situation during childhood) and for non-students (ie, high professional position, stable professional position, teleworking).
To test the robustness of the findings, we conducted sensitivity analyses using alternative cut-off for depressive, anxiety symptoms and perceived stress: (a) cut-offs representing severe depressive symptoms (PHQ-9 $\geq 15$ ), severe anxiety symptoms (GAD-7 $\geq 15$ ) and mild perceived stress ( $\geq 5$ ), (b) cut-offs representing the full spectrum of depressive (minimal: 0-9; mild: 10-14; moderate: 15-19; severe: 20-27) and anxiety symptoms (minimal: $0-4$; mild: 5-9; moderate: 10-14; severe: 15-21). We also performed sensitivity analyses among the complete case population to test the robustness of results regarding the imputation process.

Our missing data analysis procedures used missing at random assumptions. We used the multivariate imputation by chained equations method of multiple multivariate imputation in SAS software (PROC MI and MIANALYZE) ${ }^{34-36}$ We independently analysed 10 copies of the data, each with suitably imputed missing values, in the multivariate linear or logistic regression analyses. We averaged estimates of the variables to give a single mean estimate and adjusted SEs according to Rubin's rules. We imputed only data from covariates using covariate data and completed the imputation process with other data collected in the CONFINS cohort (having a child, housing type before and during the lockdown, self-rated health and self-rated quality of life before the lockdown). We performed additional imputations for the student subsample since paid activity and financial conditions during childhood had missing data.

We performed all analyses using the SAS statistical software (SAS V.9.3).

\section{RESULTS}

\section{Participants and sample description}

Of the 2344 participants enrolled in the CONFINS study, 2309 were eligible for the study, among which 2260 were included in the analysis of depressive and anxiety symptoms and 1919 for suicidal thoughts and perceived stress (figure 1). Table 1 and online supplemental table S1 provide supplementary material describing details of the study sample. Students represented $59 \%$ of the total sample ( $\mathrm{n}=1335$ vs 925 non-students). Compared with non-students, mean age in the student sample was about 16 years lower (mean=23.3 vs 40.1 ) whereas sex ratio was similar ( $3 / 4$ female) in both samples. Students had less frequently a partner $(48.1 \%$ vs $76.3 \%)$ and were slightly more frequently at risk for severe forms for COVID-19 (35.4\% vs 24.0\%). Importantly, both populations were similar regarding history of psychiatric disorders (about 23\%), education level (with a majority of more than a second-year university level) and proportion of individual working or studying in health domains (about 40\%). Although non-students spent the lockdown more frequently in their usual place than students $(88.2 \%$ vs $63.4 \%$ ), the quality of lockdown accommodation (eg, surface, outdoor space) was similar for both populations. Students were fewer than non-students to be in a high-risk 


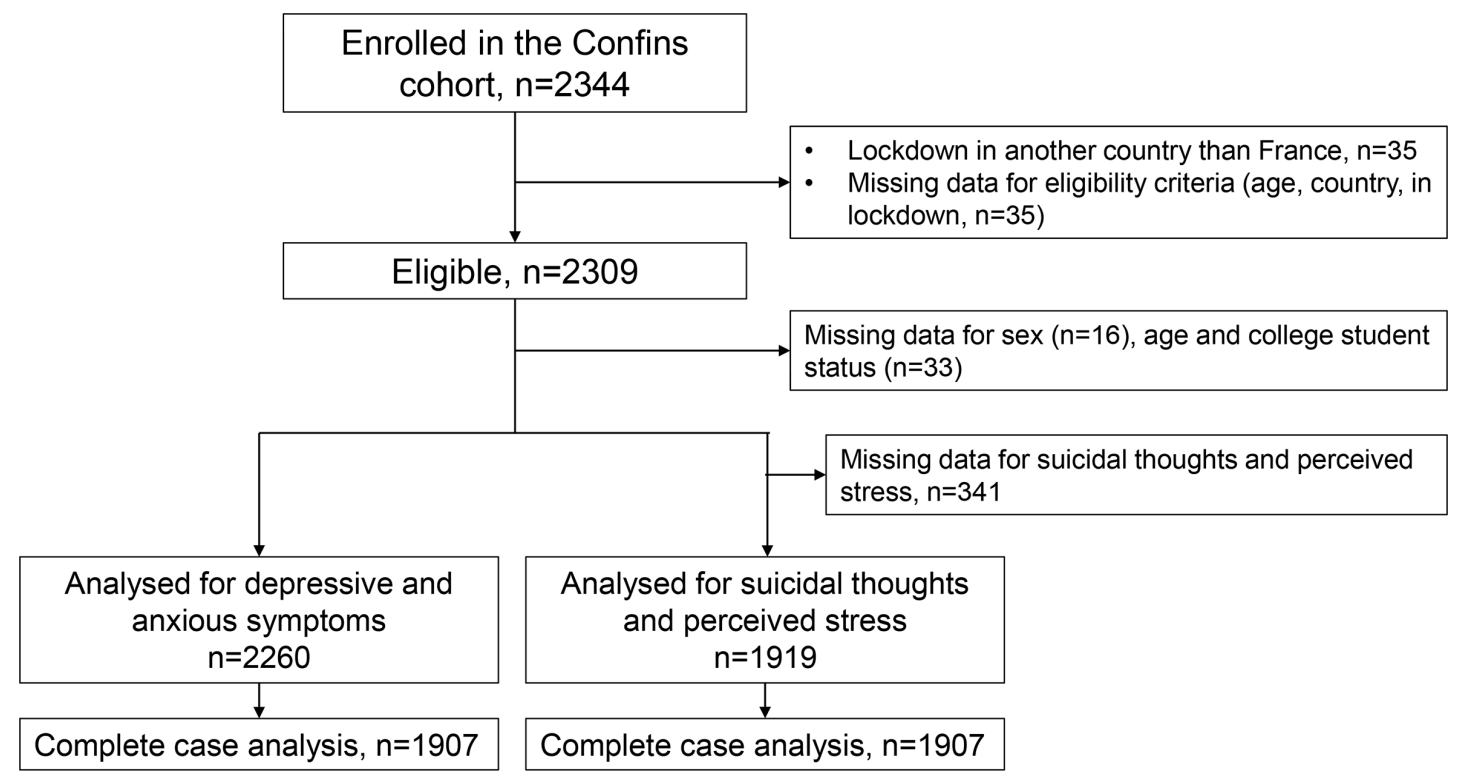

Figure 1 Flow chart for sample selection, CONFINS cohort, France, 2020.

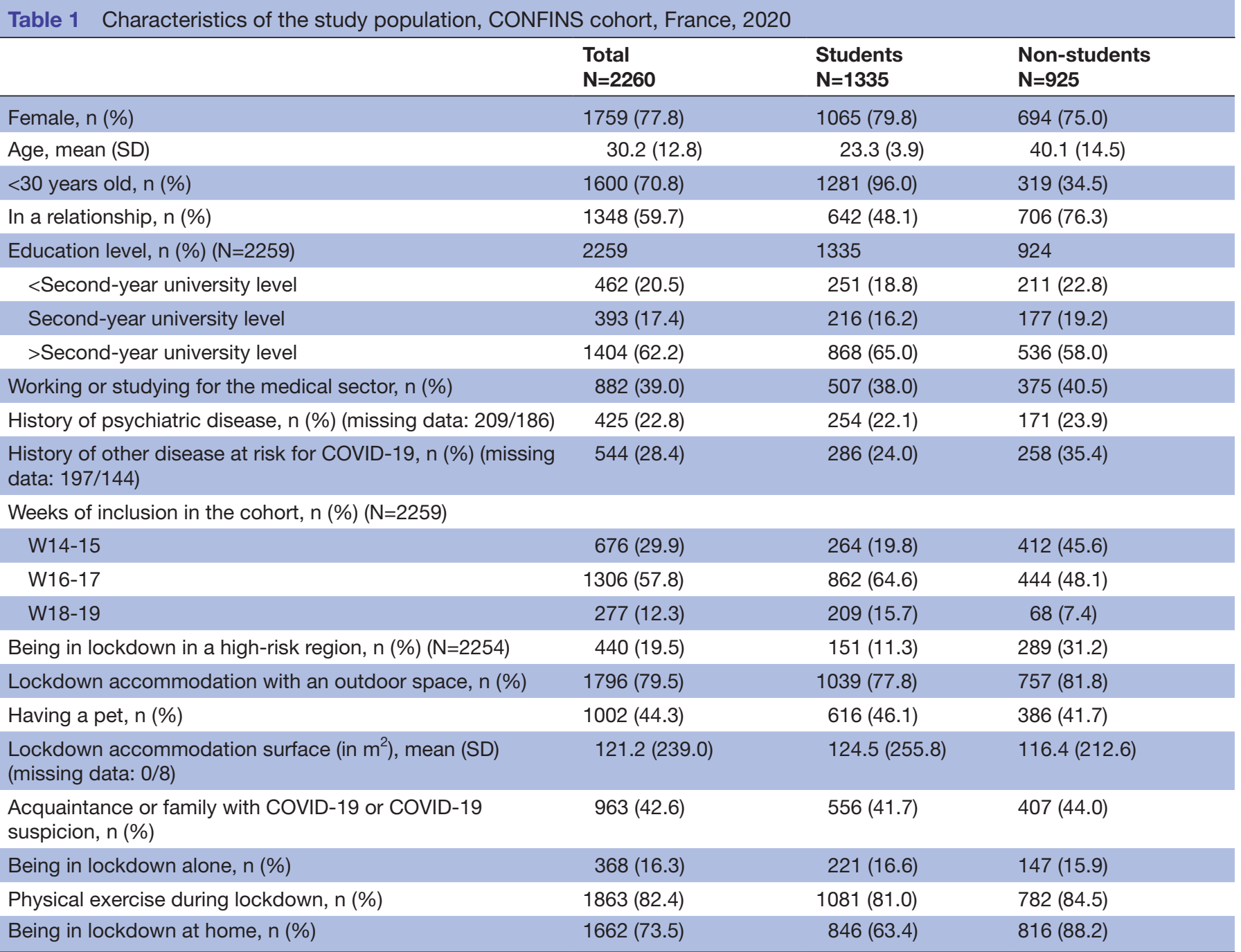




\begin{tabular}{|c|c|c|c|}
\hline & $\begin{array}{l}\text { Total } \\
\mathrm{N}=2260\end{array}$ & $\begin{array}{l}\text { Students } \\
\mathrm{N}=1335\end{array}$ & $\begin{array}{l}\text { Non-students } \\
\mathrm{N}=925\end{array}$ \\
\hline \multicolumn{4}{|l|}{ Depressive symptoms } \\
\hline PHQ-9 score $\geq 10, n(\%)$ & $584(25.8)$ & $434(32.5)$ & $150(16.2)$ \\
\hline \multicolumn{4}{|l|}{ Anxiety symptoms } \\
\hline \multirow{2}{*}{ GAD-7 score $\geq 10, n(\%)$} & $457(20.2)$ & $321(24.0)$ & $136(14.7)$ \\
\hline & $\begin{array}{l}\text { Total } \\
\mathrm{N}=1919\end{array}$ & $\begin{array}{l}\text { Students } \\
\mathrm{N}=1191\end{array}$ & $\begin{array}{l}\text { Non-students } \\
\mathrm{N}=728\end{array}$ \\
\hline Suicidal thoughts, n (\%) & $194(10.1)$ & $139(11.7)$ & $55(7.6)$ \\
\hline \multicolumn{4}{|l|}{ Perceived stress } \\
\hline Perceived stress $\geq 7, \mathrm{n}(\%)$ & $555(28.9)$ & $394(33.1)$ & $161(22.1)$ \\
\hline
\end{tabular}

GAD-7, Generalised Anxiety Disorder-7; PHQ-9, Patient Health Questionnaire-9.

region regarding COVID-19 (11.3\% vs 31.2\%) and they were enrolled in the cohort later (mostly during weeks 16-17).

\section{Student status and mental health conditions}

Students had more frequently depressive symptoms ( $32.5 \%$ vs $16.2 \%)$, anxiety symptoms $(24.0 \%$ vs $14.7 \%)$, suicidal thoughts $(11.7 \%$ vs $7.6 \%)$ and perceived stress $(33.1 \%$ vs $22.1 \%$ ) than non-students (table 2$)$. In multivariate models, student status was associated with an increased probability to report depressive symptoms (OR fully adjusted (aOR) $=1.58 ; 95 \%$ CI 1.17 to 2.14 ), anxiety symptoms (ORa $=1.51 ; 95 \%$ CI 1.10 to 2.07$)$ and perceived stress $(\mathrm{ORa}=1.70,95 \%$ CI 1.26 to 2.29$)$, independently from covariates related or not to the COVID-19 pandemic and lockdown (table 3). For suicidal thoughts, the ORs were in the same range $(\mathrm{ORa}=1.57 ; 95 \%$ CI 0.97 to 2.53) but did not reach statistical significance.

Sensitivity analyses showed consistent results when analyses were performed among the complete case population and with different cut-offs (results presented in online supplemental table S1). When both samples

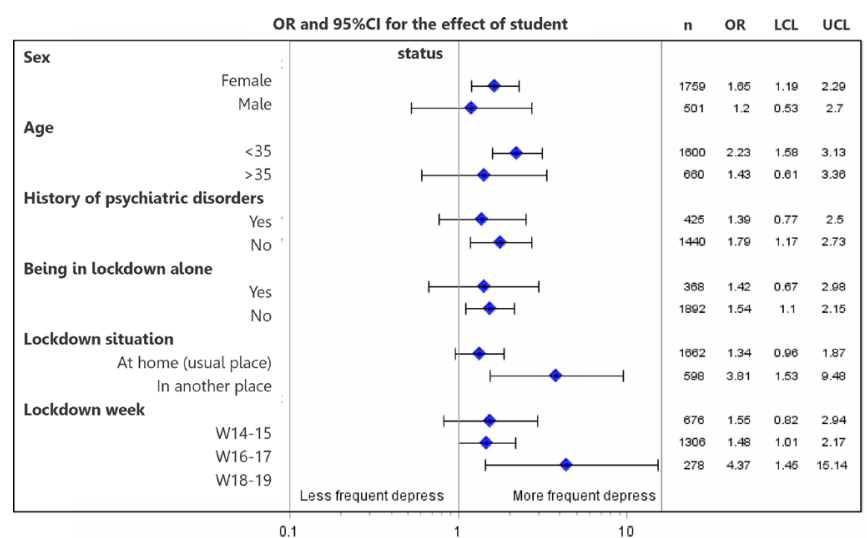

Figure 2 Forest plot representing the effect of student status on depressive symptoms according to several profiles, CONFINS cohort, France, 2020. Logistic regression model adjusted for sex, age, being in a relationship, education level, working or studying for the medical sector, history of psychiatric disease, history of other disease at risk for COVID-19, week of inclusion in the cohort, being in lockdown in a high-risk region, acquaintance or family with COVID-19 or COVID-19 suspicion, being in lockdown alone, lockdown accommodation with an outdoor space, having a pet, lockdown accommodation surface, physical activity during lockdown. LCL, lower confidence level; UCL, upper confidence level.

were restricted to young adults $(\leq 30)$, students still had a higher risk of depressive symptoms $(\mathrm{ORa}=1.54 ; 95 \% \mathrm{CI}$ 1.03 to 2.29$)$, anxiety symptoms $(\mathrm{ORa}=1.60 ; 95 \%$ CI 1.04 to 2.45) and perceived stress $(\mathrm{ORa}=1.59 ; 95 \%$ CI 1.07 to 2.34) (results presented in online supplemental table S3).

\section{Stratified analyses}

Students reported consistently more frequently depressive symptoms than non-students irrespective of the strata: female, male, with a history of psychiatric disorders or according to various lockdown conditions (eg, being in lockdown alone) (figure 2). In explicative models

Table 3 Effect of college student status on mental health conditions during COVID-19 lockdown, estimated with multivariate logistic regression analysis with imputed data on covariates, CONFINS cohort, France, 2020

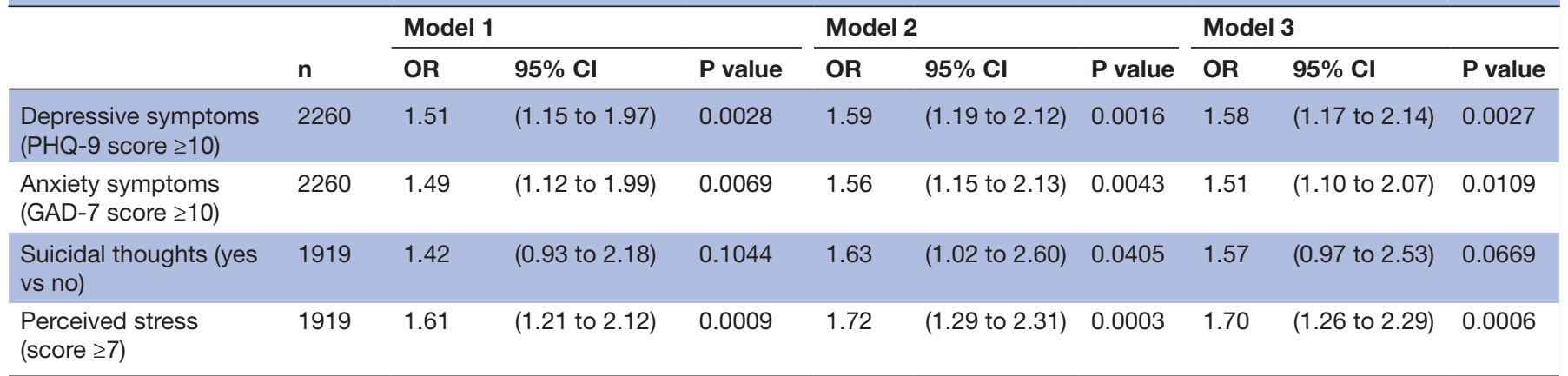

Model 1 adjusted for sex and age; model 2 adjusted for sex, age, being in a relationship, education level, working or studying for the medical sector, history of psychiatric disease, history of other disease at risk for COVID-19; model 3 adjusted for sex, age, being in a relationship, education level, working or studying for the medical sector, history of psychiatric disease, history of other disease at risk for COVID-19, week of inclusion in the cohort, being in lockdown in a high-risk region, acquaintance or family with COVID-19 or COVID-19 suspicion, being in lockdown alone, lockdown accommodation with an outdoor space, having a pet, lockdown accommodation surface, physical activity during lockdown.

GAD-7, Generalised Anxiety Disorder-7; PHQ-9, Patient Health Questionnaire-9. 
for mental health conditions, we found shared factors between students and non-students: history of psychiatric disorders (eg, for depressive symptoms: $\mathrm{OR}=2.80$, 95\% CI 2.06 to 3.82 among students and $\mathrm{OR}=3.10,95 \%$ CI 1.99 to 4.81 among non-students) and physical exercise during lockdown which was associated with less frequent mental health disturbances (eg, for depressive symptoms: $\mathrm{OR}=0.61,95 \%$ CI 0.44 to 0.83 among students and $\mathrm{OR}=0.52,95 \% \mathrm{CI} 0.32$ to 0.83 among non-students). Some potentially aggravating factors of lockdown were associated with more frequent mental health disturbances, especially among students. Indeed, being isolated in lockdown was associated with depressive symptoms only among students (OR=1.54, 95\% CI 1.04 to 2.28) compared with non-students $(\mathrm{OR}=0.90,95 \%$ CI 0.50 to 1.63). Other factors were protective only for students, like being in lockdown at home $(\mathrm{OR}=0.75,95 \%$ CI 0.57 to 0.99 for students vs $\mathrm{OR}=1.88,95 \%$ CI 0.85 to 4.18 for non-students). Detailed results of explicative models are available in online supplemental table S4 and S5.

\section{DISCUSSION}

In this large sample of adults observed during the general lockdown, although we found a high level of mental health disturbances in all participants, students had a higher prevalence of mental health problems than nonstudents. In multivariate models adjusting for a large variety of potential confounding factors, students had a more than $50 \%$ increased risk of mental health problems compared with non-students, including depressive symptoms, anxiety and perceived stress. This increased risk was also observed in participants with or without a history of psychiatric diseases, in various lockdown situations, or when both samples were restricted to young adults. Finally, lockdown conditions like isolation that could potentially aggravate mental health disorders, had a higher impact on students.

\section{Interpretation}

The high frequency of mental health disturbances found in our study corroborates previous research conducted separately among students and other adults. In the general non-student population, several studies reported a prevalence between $17 \%$ and $28 \%$ for depressive symptoms, between $14 \%$ and $45 \%$ for anxiety symptoms and between $8 \%$ and $27 \%$ for stress. ${ }^{14}{ }^{15} 37-41$ Previous studies performed in college students during the lockdown reported a prevalence of depressive symptoms between $9 \%$ and $39 \%$, anxiety symptoms between $25 \%$ and $39 \%$ and $28 \%$ for stress. ${ }^{1819212225-2742}$ As all these figures are drawn from different settings and different populations, it is not possible to compare students and non-students and to establish differences. In the CONFINS study, students and non-students were recruited in a similar fashion and filled-in the same questionnaires and scales. We could therefore make direct comparison and our analyses strongly suggest that there is a higher risk of mental health disturbances during lockdown in students compared with non-students, even after taking into account all measured potential confounders.

To explain this higher mental health risk among college students during general lockdown, several mechanisms could be discussed: disturbance in mood homeostasis during lockdown (ie, failure to stabilise mood via mood-modifying activities), ${ }^{43}$ lack of social and familial support, ${ }^{44-46}$ specific vulnerability of young adults already known that could be exacerbated by pandemic and lockdown (eg, worries about the future and employment). ${ }^{194748}$

We also found that factors related to COVID-19 pandemic or lockdown conditions had a higher impact on mental health in students than in non-students, highlighting again mental health vulnerability of college students. Finally, we confirmed previous observations that being a woman, having a low education level, having a history of psychiatric disorders and being isolated were associated with mental health disturbances among both students and non-students. ${ }^{25} 264950$

\section{Strengths and limitations}

The strengths of our study include the large sample size, the standardised assessment tools used for mental health conditions and broad adjustment for other factors (related or not to the COVID-19 pandemic and lockdown). Some limitations should however be taken into consideration. First, a selection bias could have arisen since participants were volunteers. Noteworthy, communication was based on similar messages for both students and non-students and it was never mentioned that students will be compared with non-students for their mental health. Therefore, the selection bias should impact similarly both groups resulting in unbiased estimates of the association between groups (students/non-students) and mental health. Even if our results are unbiased (with good internal validity), our findings may not be generalisable to other settings and other populations. Samples of both students and nonstudents are likely to not be representative of the general population. Indeed, we observed an over-representation of women $(80 \%$ in our sample for college students vs $56 \%$ according to the French government). Noteworthy, our college student sample was quite similar from other college students' studies conducted in France (the i-Share cohort $^{5152}$ or the COSAMe study ${ }^{27}$ ). Repartition of educational level, living conditions and psychiatric history were rather similar across studies (near one-third of freshman, one-sixth living alone and one-sixth with a history of psychiatric disorder). Additionally, subgroup analyses (across several strata of characteristics closely linked with mental health) shown consistent results bringing strong evidence to a higher risk of mental health disturbance in college students whatever the particular distribution of our sample.

Second, the association between student status and mental health disturbances during lockdown could be explained partly by unmeasured factors, even if we 
have included a large range of covariates to prevent a confounding bias. The age difference was important between both groups and age-associated potential confounders could not be completely neutralised by adjusting on age. This is why we performed a sensitivity analysis comparing students to the youngest non-students ( $\leq 30$ years). As we found consistent results, we are rather confident that our findings were not driven by the age difference.

Finally, our study only investigates cross-sectional data and we could not explore the lifting of lockdown and the effect of successive lockdowns on mental health in these two populations. This has been explored separately in students and in non-students in previous studies but again there is no head-to-head comparison. ${ }^{23} 2453$

\section{CONCLUSIONS}

Our results confirm the vulnerability of college students during pandemic period and lockdown regarding mental health. Screening, support and interventions adapted to students should be considered during lockdown episodes.

Acknowledgements The authors are indebted to the participants of the CONFINS cohort for their commitment and cooperation and to the entire i-Share (Elena Milesi, Marie Mougin, Edwige Pereira, Garance Perret, Clothilde Pollet, Aude Pouymayou), Kappa Santé (Christophe Brunat, David Clément, Clément Leclercq) and Kap Code (Vanessa Marie-Joseph, Juliette Olivier, Salma Rzin) staff for their expert contribution and assistance, especially in this very particular context of pandemic and lockdown.

Contributors CT and SS are the principal investigators of the CONFINS cohort. JA and CT developed the concept and the design of the current study. JA performed the data analysis and drafted the manuscript. IM, MM, SK and MT participated actively in the creation of the CONFINS questionnaires and brought epidemiological, psychological and psychiatric expertise to the interpretation of the results. NT, MP, $\mathrm{RG}$ and $\mathrm{AM}$ brought technical expertise for the electronic case report form, datamanagement and statistical considerations. All coauthors provided critical revisions and approved the final version of the manuscript for submission.

Funding The i-Share and CONFINS team are currently supported by an unrestricted grant of the Nouvelle-Aquitaine Regional Council (Conseil Régional Nouvelle-Aquitaine, grant $\mathrm{N}^{\circ} 4370420$ ). It has also received grants from the Nouvelle-Aquitaine Regional Health Agency (Agence Régionale de Santé NouvelleAquitaine, grant N6066R-8 R-8), Public Health France (Santé Publique France, grant $N^{\circ}$ 19DPPP023-0) and The National Institute against cancer INCa (grant NoINCa_11502). MM was supported by a PhD grant of the Nouvelle-Aquitaine Regional Council (grant No 17-EURE-0019).

Disclaimer The funding bodies were neither involved in the study design, or in the collection, analysis, or interpretation of the data.

Competing interests None declared.

Patient consent for publication Not required.

Ethics approval The study follows the principles of the Declaration of Helsinki and the collection, storage and analysis of the data comply with the General Data Protection Regulation (EU GDPR). The study was approved by the French Committee for the Protection of Individuals (Comité de Protection des Personnes-CPP IDF X, nr. 46-2020) and by the National Commission on Informatics and Liberty (Commission Nationale de I'Informatique et des Libertés-CNIL, nr. MLD/MFI/ AR205600).Participants were informed on the nature and purpose of the study and provided online consent (consent form is provided in the submission document).

Provenance and peer review Not commissioned; externally peer reviewed.

Data availability statement Data are available upon reasonable request. Because of the sensitive nature of the data collected for this study, requests to access the dataset from qualified researchers trained in human subject confidentiality protocols may be sent to the CONFINS cohort team (www.confins.org).
Supplemental material This content has been supplied by the author(s). It has not been vetted by BMJ Publishing Group Limited (BMJ) and may not have been peer-reviewed. Any opinions or recommendations discussed are solely those of the author(s) and are not endorsed by BMJ. BMJ disclaims all liability and responsibility arising from any reliance placed on the content. Where the content includes any translated material, BMJ does not warrant the accuracy and reliability of the translations (including but not limited to local regulations, clinical guidelines, terminology, drug names and drug dosages), and is not responsible for any error and/or omissions arising from translation and adaptation or otherwise.

Open access This is an open access article distributed in accordance with the Creative Commons Attribution Non Commercial (CC BY-NC 4.0) license, which permits others to distribute, remix, adapt, build upon this work non-commercially, and license their derivative works on different terms, provided the original work is properly cited, appropriate credit is given, any changes made indicated, and the use is non-commercial. See: http://creativecommons.org/licenses/by-nc/4.0/.

\section{ORCID iDs}

Julie Arsandaux http://orcid.org/0000-0002-3036-5866

Ilaria Montagni http://orcid.org/0000-0003-0076-0010

Shérazade Kinouani http://orcid.org/0000-0003-2921-008X

Christophe Tzourio http://orcid.org/0000-0002-6517-2984

\section{REFERENCES}

1 Kessler RC, Amminger GP, Aguilar-Gaxiola S, et al. Age of onset of mental disorders: a review of recent literature. Curr Opin Psychiatry 2007;20:359-64.

2 Kovess-Masfety V, Leray E, Denis L, et al. Mental health of college students and their non-college-attending Peers: results from a large French cross-sectional survey. BMC Psychol 2016;4:20.

3 Verger P, Guagliardo V, Gilbert F, et al. Psychiatric disorders in students in six French universities: 12-month prevalence, comorbidity, impairment and help-seeking. Soc Psychiatry Psychiatr Epidemiol 2010;45:189-99.

4 Verger P, Combes J-B, Kovess-Masfety V, et al. Psychological distress in first year university students: socioeconomic and academic stressors, mastery and social support in young men and women. Soc Psychiatry Psychiatr Epidemiol 2009;44:643-50.

5 Augesti G, Lisiswanti R, Saputra O. Differences in stress level between first year and last year medical students in medical facultyof Lampung university. J Major2015;4 http://juke.kedokteran.unila.ac.id/ index.php/majority/article/view/578

6 Beiter R, Nash R, McCrady M, et al. The prevalence and correlates of depression, anxiety, and stress in a sample of college students. $J$ Affect Disord 2015;173:90-6.

7 Cheung DK, Tam DKY, Tsang MH, et al. Depression, anxiety and stress in different subgroups of first-year university students from 4-year cohort data. J Affect Disord 2020;274:305-14.

8 Galea S, Merchant RM, Lurie N. The mental health consequences of COVID-19 and physical distancing: the need for prevention and early intervention. JAMA Intern Med 2020;180:817-8.

9 WHO. WHO coronavirus disease (COVID-19) Dashboard | who coronavirus disease (COVID-19) Dashboard. Available: https:// covid19. who.int/table?tableChartType=heat [Accessed 03 Sep 2020].

10 Barbisch D, Koenig KL, Shih F-Y. Is there a case for quarantine? perspectives from SARS to Ebola. Disaster Med Public Health Prep 2015;9:547-53.

11 Brooks SK, Webster RK, Smith LE, et al. The psychological impact of quarantine and how to reduce it: rapid review of the evidence. The Lancet 2020;395:912-20.

12 Xiong J, Lipsitz O, Nasri F, et al. Impact of COVID-19 pandemic on mental health in the general population: a systematic review. $J$ Affect Disord 2020;277:55-64.

13 Rajkumar RP. COVID-19 and mental health: a review of the existing literature. Asian J Psychiatr 2020;52:102066.

14 Wang C, Pan R, Wan X, et al. Immediate psychological responses and associated factors during the initial stage of the 2019 coronavirus disease (COVID-19) epidemic among the general population in China. Int J Environ Res Public Health 2020;17:1729.

15 Gualano MR, Lo Moro G, Voglino G, et al. Effects of Covid-19 Lockdown on mental health and sleep disturbances in Italy. Int $J$ Environ Res Public Health 2020;17:4779.

16 Rodríguez-Rey R, Garrido-Hernansaiz H, Collado S. Psychological impact and associated factors during the initial stage of the coronavirus (COVID-19) pandemic among the general population in Spain. Front Psychol 2020;11:1540. 
17 Husky MM, Kovess-Masfety V, Swendsen JD. Stress and anxiety among university students in France during Covid-19 mandatory confinement. Compr Psychiatry 2020;102:152191.

18 Cao W, Fang Z, Hou G, et al. The psychological impact of the COVID-19 epidemic on college students in China. Psychiatry Res 2020;287:112934.

19 Tang W, Hu T, Hu B, et al. Prevalence and correlates of PTSD and depressive symptoms one month after the outbreak of the COVID-19 epidemic in a sample of home-quarantined Chinese university students. J Affect Disord 2020;274:1-7.

20 Hoyt LT, Cohen AK, Dull B, et al. "Constant Stress Has Become the New Normal": Stress and Anxiety Inequalities Among U.S. College Students in the Time of COVID-19. J Adolesc Health Off Publ Soc Adolesc Med 2021;68:270-6.

$21 \mathrm{Yu}$ Y, She R, Luo S, et al. Factors influencing depression and mental distress related to COVID-19 among university students in China: online cross-sectional mediation study. JMIR Ment Health 2021;8:e22705.

22 Padrón I, Fraga I, Vieitez L, et al. A study on the psychological wound of COVID-19 in university students. Front Psychol 2021;12:589927.

23 Savage MJ, James R, Magistro D, et al. Mental health and movement behaviour during the COVID-19 pandemic in UK university students: prospective cohort study. Ment Health Phys Act 2020;19:100357.

24 Meda N, Pardini S, Slongo I, et al. Students' mental health problems before, during, and after COVID-19 lockdown in Italy. J Psychiatr Res 2021;134:69-77.

25 Sun S, Goldberg SB, Lin D, et al. Psychiatric symptoms, risk, and protective factors among university students in quarantine during the COVID-19 pandemic in China. Global Health 2021;17:15.

26 Bourion-Bédès S, Tarquinio C, Batt M, et al. Psychological impact of the COVID-19 outbreak on students in a French region severely affected by the disease: results of the PIMS-CoV 19 study. Psychiatry Res 2021;295:113559.

27 Wathelet M, Duhem S, Vaiva G, et al. Factors associated with mental health disorders among university students in France confined during the COVID-19 pandemic. JAMA Netw Open 2020;3:e2025591.

28 Kroenke K, Spitzer RL, Williams JBW. The PHQ-9. J Gen Intern Med 2001;16:606-13.

29 Pfizer. Patient health questionnaire (PHQ) screeners. Available: http:// www. phqscreeners.com [Accessed 4 Jun 2019].

30 Arthurs E, Steele RJ, Hudson M, et al. Are scores on English and French versions of the PHQ-9 comparable? an assessment of differential item functioning. PLoS One 2012;7:e52028.

31 Manea L, Gilbody S, McMillan D. Optimal cut-off score for diagnosing depression with the patient health questionnaire (PHQ-9): a meta-analysis. CMAJ 2012;184:E191-6.

32 Spitzer RL, Kroenke K, Williams JBW, et al. A brief measure for assessing generalized anxiety disorder: the GAD-7. Arch Intern Med 2006;166:1092-7.

33 Micoulaud-Franchi J-A, Lagarde S, Barkate G, et al. Rapid detection of generalized anxiety disorder and major depression in epilepsy: validation of the GAD-7 as a complementary tool to the NDDI-E in a French sample. Epilepsy Behav 2016;57:211-6.

34 Janssen KJM, Donders ART, Harrell FE, et al. Missing covariate data in medical research: to impute is better than to ignore. $J$ Clin Epidemiol 2010;63:721-7.

35 Rubin DB, Schenker N. Multiple imputation in health-care databases: an overview and some applications. Stat Med 1991;10:585-98.
36 Schafer JL. Analysis of incomplete multivariate data. CRC Press, 1997.

37 Bäuerle A, Teufel M, Musche V. Increased generalized anxiety, depression and distress during the COVID-19 pandemic: a crosssectional study in Germany. J Public Health 2020.

38 Choi EPH, Hui BPH, Wan EYF. Depression and anxiety in Hong Kong during COVID-19. Int J Environ Res Public Health 2020;17:3740.

39 González-Sanguino C, Ausín B, Castellanos Miguel Ángel, et al. Mental health consequences during the initial stage of the 2020 coronavirus pandemic (COVID-19) in Spain. Brain Behav Immun 2020;87:172-6.

40 Mazza C, Ricci E, Biondi S, et al. A nationwide survey of psychological distress among Italian people during the COVID-19 pandemic: immediate psychological responses and associated factors. Int J Environ Res Public Health 2020;17:3165.

41 Ozamiz-Etxebarria N, Idoiaga Mondragon N, Dosil Santamaría M. Psychological symptoms during the two stages of Lockdown in response to the COVID-19 outbreak: an investigation in a sample of citizens in northern Spain. Front Psychol2020;11.

42 Odriozola-González P, Planchuelo-Gómez Álvaro, Irurtia MJ, et al. Psychological effects of the COVID-19 outbreak and lockdown among students and workers of a Spanish university. Psychiatry Res 2020;290:113108.

43 Taquet M, Quoidbach J, Fried El. Mood homeostasis before and during the coronavirus disease 2019 (COVID-19) Lockdown among students in the Netherlands. JAMA Psychiatry2020.

44 Gariépy G, Honkaniemi H, Quesnel-Vallée A. Social support and protection from depression: systematic review of current findings in Western countries. Br J Psychiatry 2016;209:284-93.

$45 \mathrm{Kmietowicz} Z$. Rules on isolation rooms for suspected covid-19 cases in GP surgeries to be relaxed. BMJ 2020;368:m707.

46 Pössel P, Burton SM, Cauley B, et al. Associations between social support from family, friends, and teachers and depressive symptoms in adolescents. $J$ Youth Adolesc 2018;47:398-412.

47 Mortier P, Cuijpers P, Kiekens G, et al. The prevalence of suicidal thoughts and behaviours among college students: a meta-analysis. Psychol Med 2018;48:554-65.

48 Twenge JM, Joiner TE, Rogers ML. Increases in depressive symptoms, suicide-related outcomes, and suicide rates among U.S. adolescents after 2010 and links to increased new media screen time. Clin Psychol Sci 2017.

49 Husky MM, Kovess-Masfety V, Gobin-Bourdet C, et al. Prior depression predicts greater stress during Covid-19 mandatory lockdown among college students in France. Compr Psychiatry 2021;107:152234.

50 Shahriarirad R, Erfani A, Ranjbar K, et al. The mental health impact of COVID-19 outbreak: a nationwide survey in Iran. Int J Ment Health Syst 2021;15:19.

51 Arsandaux J, Michel G, Tournier M, et al. Is self-esteem associated with self-rated health among French college students? A longitudinal epidemiological study: the i-Share cohort. BMJ Open 2019;9:e024500.

52 Macalli M, Côté S, Tzourio C. Perceived parental support in childhood and adolescence as a tool for mental health screening in students: a longitudinal study in the i-Share cohort. J Affect Disord 2020;266:512-9.

53 Pierce M, Hope H, Ford T, et al. Mental health before and during the COVID-19 pandemic: a longitudinal probability sample survey of the UK population. Lancet Psychiatry 2020;7:883-92. 